\section{Chinese Poetry}

An Anthology of Major Modes

and Genres

Second Edition, Revised

Wai-lim Yip, editor and translator

This is the first paperback edition of a classic anthology of Chinese poetry. Spanning two thousand years these 150 poems cover all major genres that students of Chinese poetry must learn. 360pp, 181 ideograms, $€ 17.95 \mathrm{pb}$

\section{Formations of Colonial Modemity in East Asia}

Tani E. Barlow, editor

The essays in this volume illustrate how valuable the analytic of colonial modernity is to the rethinking of contemporary history.

456pp, 40 b\&w photos, $£ 17.95 \mathrm{pb}$

\section{Comfort Women}

Chungmoo Choi, editor

This special issue of positions explores the devastated terrain where the peculiar form of East Asian colonial modernity and militarism intersects with gender and sexuality.

275pp, $£ 11.00 \mathrm{pb}$

\section{Producing Guanxi}

Sentiment, Self, and Subculture in a North China Village

Andrew B. Kipnis

"This is a rich and well-reflected ethnographic text that captures a core feature of both traditional and contemporary Chinese culture."

-Mayfair Yang

264pp, 11 b\&w photos, $£ 15.95 \mathrm{pb}$

\section{Manufacturing Confucianism}

Chinese Traditions and

\section{Universal Civilizations}

\section{Lionel M. Jensen}

In revealing that the figure of Confucius was invented by Jesuit priests, Jensen reconstructs the cultural consequences of the encounter between the West and China. 408pp, 13 illus., $£ 18.95 \mathrm{pb}$

\section{National Past-Times}

Narrative, Representation, and Power in Modern China

\section{Ann S. Anagnost}

Anagnost explores the fashioning and refashioning of modern Chinese subjectivity as it relates to the literal and figurative body of the nation. Body, Commodity, Text 272pp, 6 b\&w photos, $€ 15.95 \mathrm{pb}$

\section{Chinese Modernism in the Era of Reforms}

Cultural Fever, Avant-Garde Fiction, and the New Chinese Cinema

\section{Zhang Xudong}

Blending history and theory, this book offers both a historical narrative and a critical analysis of the cultural visions and experiences of China's post-Mao era.

Post-Contemporary Interventions 496pp, 12 b\&w photos, $£ 20.95 \mathrm{pb}$

\section{Duke University Press}

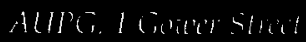

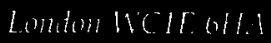

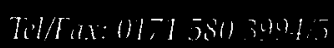




\section{Lit Can your library afford not to subscribe to}
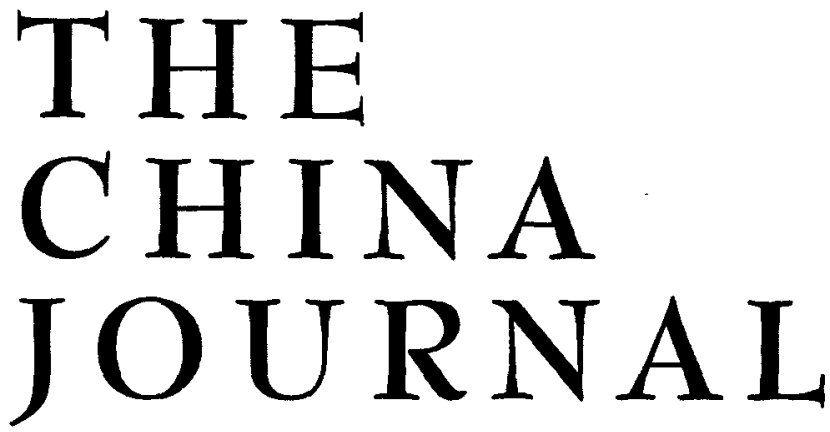

Consistently penetrating commentary.

Lowell Dittmer, University of California, Berkeley

Up-to-date research, fresh ideas, and the thoughts of the leading specialists on all aspects of contemporary China. Lucien Pye, MIT

Has now become must reading for any serious student of contemporary China.

Martin K. Whyte, George Washington University

Should be regularly consulted by everybody who wants to keep abreast of developments in the academic disciplines concerned with China.

Jurgen Domes, University of Saarlandes, Germany

This is one of the few journals that I read cover to cover. James L. Watson, Harvard University

Subscription Rates (two 230-page issues per year - plus a free issue for new subscribers): Within Australia: $\$ 25$ per year, students $\$ 20$, institutions $\$ 40$. Outside Australia: US\$25 per year, students US\$20, institutions US\$40; or the equivalent in other currencies. New 3-year subscriptions: $\$ 60 /$ US\$60, institutions $\$ 100$ - plus 2 complimentary issues.

I would like a: $\square$ 1-year $\square$ 3-year subscription

$\square$ Enclosed is my check (payable to The China Journal)

$\square$ Please charge to my $\square$ Bankcard $\square$ Mastercard $\square$ visa

Card No.

Exp. Date

Name

Signature

Address

Payments to: Contemparary China Centre, RSPAS, The Australian National University, Canbera, ACT 0200. 


\section{Hong Kong Writing from Renditions}

\section{Nos. $47 \& 48$}

Featuring prose and fiction by both established authors and new voices, as well as poetry by young Hong Kong poets who emerged in the 1990s. Copiously illustrated. US\$25

\section{BY XI XI}

\section{Marvels of a Floating City}

$\mathrm{Xi} \mathrm{Xi}$ weaves Western culture and local perception, reality and fantasy into narratives of the hopes, anger and fears which grip the people of Hong Kong in this crucial period of their history. ISBN 962-7255-18-1 US\$14.95

\section{A Girl Like Me and Other Stories} (enlarged edition)

ISBN 962-7255-19-X US\$14.95

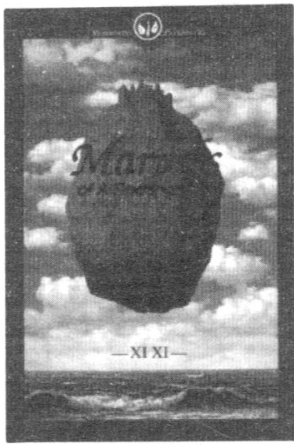

US\$14.95

\section{BY LIU YICHANG}

The Cockroach and Other Stories ISBN 962-7255-15-7 US\$14.95
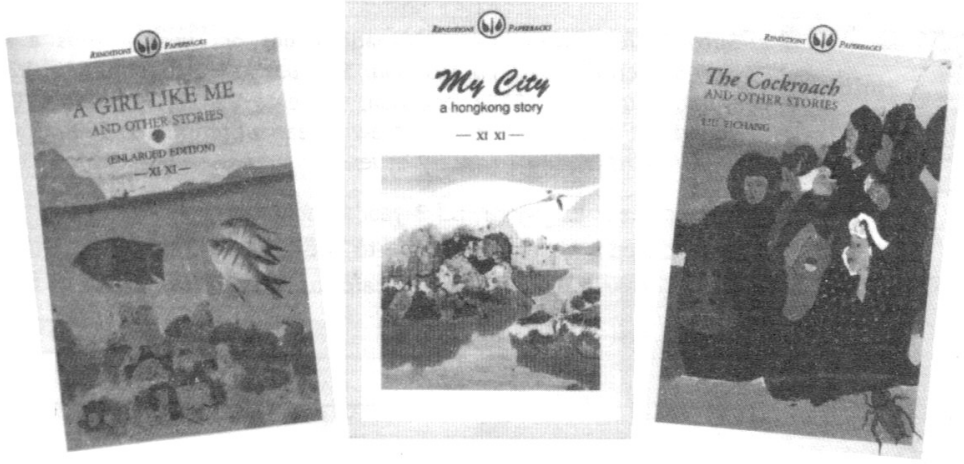

\section{Renditions}

Chinese University of Hong Kong, Shatin, NT., Hong Kong

Telephone (852) $26097407 \quad$ Fax (852) 26035149

e-mail: renditions@cuhk.edu.hk website: http://www.cuhk.edu.hk/renditions 